\title{
Effect of eradication of HCV infection by direct-acting antivirals in diabetic HCV- infected patients as regards glycemic control
}

Mohamed Mohei El Badry ${ }^{1 *}$ D, Doaa Abdelhady Ali ${ }^{1}$, Noha Hamdy Eltaweel ${ }^{2}$ and Marwa A. Abdel-Wahed ${ }^{3}$

\begin{abstract}
Background: A burden of data suggests that insulin signaling could be impaired with hepatitis $C$ virus infection, and this boost the onset of type 2 diabetes mellitus beyond and in addition to the histological effect on the associated liver disease. We aimed to evaluate the hemoglobin A1c (HbA1c) levels before and after therapy with direct-acting antivirals (DAAs) in HCV-diabetic patients who achieved sustained virological response (SVR) at Aswan Fever Hospital. This prospective study was conducted at the Viral Hepatitis Treatment Center, Aswan Fever Hospital, Aswan, Egypt, between November 2017 and May 2018. A total of 85 randomly selected diabetic patients (type 2 diabetes mellitus) with chronic HCV infection were received sofosbuvir and daclatasvir as a dual therapy for 3 months, then followed up for week 12 after the end of DAA therapy, Changes in the levels of hemoglobin A1c ( $\mathrm{HbA1c}$ ) were measured at baseline then 12 weeks after the end of treatment with DAAs.

Results: Thirty-two patients (37.6\%) showed a significant glycemic improvement after receiving DAAs therapy; in the form of $>1 \%$ reduction in $\mathrm{HbA} 1 \mathrm{c}$ level $(p$ value $<0.001$ ). Their baseline mean $\mathrm{HbA1c}$ level was $7.98 \pm 0.62 \%$ which was significantly improved 12 weeks after the end of therapy (SVR) to reach a level of $6.88 \pm 0.81 \%$. Meanwhile, 53 patients (62.4\%) had a baseline mean $\mathrm{HbA1c}$ of $8.24 \pm 0.64 \%$ and a post-treatment mean $\mathrm{HbA1c}$ level of $8.34 \pm 0.61 \%$ ( $p$ value $=0.083$ ).
\end{abstract}

Conclusion: DAAs-based eradication of HCV is associated with improved glycemic control in $37.6 \%$ of patients with diabetes as evidenced by a significant reduction of mean HbA1c.

Keywords: Direct-acting antiviral drugs (DAAs), HCV, Glycated hemoglobin (HA1C), Glycemic control, Eradication, Diabetic

\section{Background}

Hepatitis C virus (HCV) affects over 185 million people, with an estimated $2.8 \%$ increase globally over the last decade. It has been estimated that HCV is the leading cause of cirrhosis and hepatocellular carcinoma (HCC) cases worldwide. Global- and region-specific estimates of HCV prevalence vary greatly $[1,2]$, but the highest

\footnotetext{
* Correspondence: melbadry2002@yahoo.com

'Department of Tropical Medicine and Gastroenterology, Faculty of Medicine, Aswan University, Aswan, Egypt

Full list of author information is available at the end of the article
}

prevalence has been reported in China, Pakistan, Nigeria, Egypt, India, and Russia which together accounted for more than half of the total infections [3].

In Egypt, $\mathrm{HCV}$ was estimated to affect $14.7 \%$ of the population; over $90 \%$ of the infections have been reported to be HCV genotype 4. The spread of chronic HCV infection in Egypt is thought to be largely due to needle re-use during mass-treatment programs for schistosomiasis during the late 1950s through the early 1980s. Unfortunately, transmission continues to occur,

\section{Springer Open}

( ) The Author(s). 2020 Open Access This article is licensed under a Creative Commons Attribution 4.0 International License, which permits use, sharing, adaptation, distribution and reproduction in any medium or format, as long as you give appropriate credit to the original author(s) and the source, provide a link to the Creative Commons licence, and indicate if changes were made. The images or other third party material in this article are included in the article's Creative Commons licence, unless indicated otherwise in a credit line to the material. If material is not included in the article's Creative Commons licence and your intended use is not permitted by statutory regulation or exceeds the permitted use, you will need to obtain permission directly from the copyright holder. To view a copy of this licence, visit http://creativecommons.org/licenses/by/4.0/. 
primarily through iatrogenic sources, such as blood transfusions, injections, and dental care [4].

It is widely recognized that there is a link between infection with HCV and type 2 diabetes mellitus (T2DM). Patients chronically infected with HCV are 4 times more likely to have T2DM than $\mathrm{HCV}$ negative subjects. Several studies focused on the treatment of HCV with pegylated interferon (peg)/ribavirin (RBV) based therapy prior to the widespread use of the new direct-acting antiviral drugs (DAAs) [5].

With recent advances, many DAAs developed and led to a more promising future for $\mathrm{HCV}$ infected patients. Excellent advantages were related to their high potency, pangenotypic coverage and intermediate to high barrier to resistance. They paved the way to the possible application of oral interferon-free regimens. In addition, these regimens can be taken once daily and may result in global HCV eradication in the near future [6].

The effect of sustained virological response (SVR) on various clinical outcomes provides another line of evidence linking HCV infection with Insulin resistance (IR). Sustained virological response (SVR) is associated with a reduction in HCC incidence, liver-related mortality, and overall mortality. A number of clinical trials demonstrate that SVR was associated also with improved IR. For instance, a longitudinal study of the Hepatitis C Antiviral Long-Term Treatment against Cirrhosis Trial found that SVR was associated with an improvement in IR [7]. Another study based on the Milan Safety Tolerability study cohort found a reduction of de novo IR development in SVR patients compared to non-SVR patients although the mean baseline and post-treatment Homeostatic Model Assessment for Insulin Resistance (HOMA) values were similar in SVR patients [8]. Gilad et al. (2019) reported that HCV eradication leads to a decrease in $\mathrm{HbA} 1 \mathrm{c} \geq 0.5 \%$ with no increase in diabetes medications or a decrease in diabetes medications with a stable $\mathrm{HbA1c}$. Thus, the association between HCV eradication and glycemic improvement has been widely postulated. However, a little is known about the exact percent of glycemic improvement within SVR patients. Therefore, the aim of this study is to evaluate the HbA1c levels before and after therapy with DAAs in HCV-diabetic patients who achieved SVR [9].

\section{Methods}

This prospective observational study was done in the Viral Hepatitis Treatment Center, Aswan Fever Hospital, Egypt, which is one of the centers affiliated to the Egyptian National Committee for Control of Viral Hepatitis $(\mathrm{NCCVH})$ in the period between November 2017 and May 2018. Preliminary, 100 randomly selected diabetic patients with chronic HCV infection who intended to receive DAAs were participated, then followed up for week
12 after the end of DAAs therapy, only 85 patients continued till the end of the study. The remaining fifteen patients were excluded due to loss of follow-up, also those who demonstrated a viremic relapse 4 weeks after the end of therapy and remained HCV-RNA positive at week 12 were excluded.

The study was performed according to the ethical guidelines of the 1975 Declaration of Helsinki after approval from the Institutional Review Board (IRB) for human subject research at the National Hepatology and Tropical Medicine Research Institute. Written informed consents were obtained from all enrolled participants before enrolment to the study. Diabetes was defined according to American Diabetes Association (ADA) guidelines and confirmed by a hemoglobin Alc > 6.5\% [10]. The SVR was defined as undetectable HCV-RNA at week 12 after the end of therapy. The stated glycemic improvement in our study was defined as a $\geq 1 \%$ reduction of baseline $\mathrm{HbA1c}$ levels. Other previous studies involving DAAs therapy reported a decline of HbA1C by $0.5-1.95 \%[9,11]$.

Patients were included in the study according to the standardized protocol for $\mathrm{HCV}$ management issued by NCCVH. Key exclusion criteria were Child-TurcottePugh (CTP) class $\mathrm{C}$, hemoglobin level $<10 \mathrm{~g} / \mathrm{dL}$, platelet count $<50,000 / \mathrm{mm} 3$, hepatocellular carcinoma (HCC) except 6 months following a successful intervention and cure with no proof of recurrence by dynamic imaging (CT, MRI), extra-hepatic malignancy except after 2 years of cure, co-infection with hepatitis B or HIV, and hypersensitivity to any of study medications. All patients included in this study were subjected to full history taking and thorough clinical examination. Baseline demographics (age, gender, and treatment medications) were recorded. Baseline laboratory investigations were done, including complete blood count $(\mathrm{CBC})$, prothrombin time (PT), international normalized ratio (INR), hemoglobin A1c (HbA1c), renal function tests (BUN, creatinine), hepatitis $B$ virus surface antigen ( $\mathrm{Hbs} \mathrm{Ag}$ ), alpha fetoprotein (AFP), and liver function tests including AST and ALT. Patients were followed up for 12 weeks after the end of DAAs therapy and post-treatment laboratory values were obtained at the time of SVR response (HCV-RNA clearance 12 weeks after the end of therapy).The analysis of $\mathrm{CBC}$ was done using Coulter LH 750 Cell Counter, measurement of PT was performed using Stago Compact Autoanalyzer using Neoplastine CI Plus supplied by Diagnostica Stago and serum chemistry was performed using Beckman Coulter AU480 Autoanalyzer, HCV (RNA) PCR using the $\mathrm{COBAS}^{\circ} \mathrm{TaqMan}^{\circ} \mathrm{HCV}$ Test v2.0. The HbA1c measurement is based on a turbidimetric inhibition immunoassay (TINIA) principle and was performed using Roche Diagnostics Cobas c 311 Autoanalyzer. 


\section{Statistical analysis}

Statistical analysis was done using IBM SPSS software version 20. The values for the biochemical markers were expressed as mean and standard deviation in case of parametric data, and as median and interquartile ranges in case of skewed data, while categorical variables were summarized using frequency measures. Independent $t$ test was used in the comparison between two groups with quantitative data and parametric distribution and Mann-Whitney test was used in the comparison between two groups with quantitative data and non-parametric distribution. Chi-square test was used in the comparison between two groups with qualitative data and Fisher exact test was used instead of the chi-square test when the expected count in any cell found to be less than 5 . Univariate analysis was performed using paired $t$ test for continuous variables. In all statistical analyses, $p<0.05$ was considered significant.

\section{Results}

This study included 85 adult diabetic patients with chronic HCV infection, 5 patients (5.8\%) of them were cirrhotic (child A) and 14 patients (16.4\%) were hypertensive; by history and clinical examinations, there were no any associated diabetic microvascular or macrovascular complications. All included patients were HCV genotype 4 . The mean (SD) diabetic duration of the enrolled patients was 11 (5.3). The baseline demographic and clinical characteristics of all included patients are summarized in Table 1. Table 2 demonstrates the statistical comparison of the post-treatment parameters in glycemic improved patients versus glycemic non-improved patients.

Statistical comparison between pre-treatment and post-treatment parameters in both glycemic improved and glycemic non-improved patients are shown in Tables 3 and 4, respectively. At the end of therapy, there was a significant decrease in hemoglobin, bilirubin, AST, ALT levels, AFP, and FIB-4 scores, in both studied groups ( $p$ value $<0.001$ ) (Table 4 ).

At the end of treatment, 32 patients (37.6\%) showed a significant improvement in the form of $>1 \%$ reduction in HbA1c level $(p$ value $<0.001$ ). Their baseline mean HbA1c level was $7.98 \pm 0.62 \%$ which was significantly improved at the end of therapy to reach a level of $6.88 \pm$ $0.81 \%$. Meanwhile, 53 patients $(62.4 \%)$ had a baseline mean HbA1c of $8.24 \pm 0.64 \%$ and a post-treatment mean HbA1c level of $8.34 \pm 0.61 \%(p$ value $=0.083)$.

\section{Discussion}

Chronic HCV infection is a major health-related burden in Egypt which affects $14.7 \%$ of the Egyptian population. Moreover, the incidence rate of HCV infection was reported to range between 2 and 6 per 1000 every year; this leads to an estimated 170,000 new cases every year to add to the 11.5 million patients suffering from the disease. Chronic infection with $\mathrm{HCV}$ is the leading cause of end-stage liver disease, HCC, and liver-related death in Egypt [12]. However, with a recent introduction of genotype 4 effective DAAs to the treatment protocol, there was a revolutionary reduction $\mathrm{HCV}$ epidemic in Egypt; DAAs combinations were reported to show high rates of SVR and pan-genotypic clinical efficacy in $\mathrm{HCV}$ genotypes 1-6 [13].

On the other hand, the current body of evidence shows a higher prevalence of T2DM among patients with chronic $\mathrm{HCV}$ infection, it was proposed that $\mathrm{HCV}$ proteins increase serine and threonine phosphorylation of insulin receptor substrate-1, which contributes to insulin resistance. In addition, $\mathrm{HCV}$ proteins enhance the release of proinflammatory cytokines such as interleukin- 6 and tumor necrosis factor- $\alpha$, which then upregulate gluconeogenesis and enhance lipid accumulation in the liver [14].

Therefore, it is presumed that effective HCV management would result in improved glycemic control in diabetic patients. A growing body of evidence has shown a promising role of effective $\mathrm{HCV}$ eradication on glycemic control of diabetic patients; previous reports showed that the change in HbA1c was greater in those who achieved SVR (0.98\%) with DAAs than in those who sustained treatment failure. Also, the use of anti-diabetic medications decreased more in patients who achieved SVR than in those who failed to achieve SVR [15].

This was further confirmed by recent studies focusing on the association of SVR achievement and the glycemic improvement in HCV patients who received DAAs regimen $[15,16]$. Meanwhile, we conducted our study only on patients who achieved SVR, in order to verify whether this suggested improvement is occurring to all patients who achieved SVR with DAAs or not.

The drop in average HbA1c level after treatment was greater in $37.6 \%$ of our included patients, from 7.98 to $6.88 \%$ (yielding a mean HA1C difference more than $1 \%$ ), than in those for whom glycemic control failed (from 8.24 to $8.34 \%$ ). Moreover, our results revealed that those who achieved a significant glycemic improvement were less likely to have hepatic fibrosis as presented by the FIB-4 score. In agreement with our findings, Abdel Alem and his colleagues reviewed the clinical records of 65 diabetic HCV patients; there were statistically significant declines in fasting plasma glucose and HbA1c values at SVR24. Notably, whatever the degree of hepatic fibrosis, the level of fasting plasma glucose and HbAlc decreased at SVR24 in comparison to the baseline level. The improvement rate of $\mathrm{HbA1c}$ was as high as $78 \%$ of the included patients [17]. 
Table 1 Baseline demographic and clinical characteristics of all included patients

\begin{tabular}{|c|c|c|c|}
\hline & $\begin{array}{l}\text { Glycemic non-improved } \\
\text { Patients }(\text { no }=53 \text { ) }\end{array}$ & $\begin{array}{l}\text { Glycemic improved } \\
\text { Patients }(\text { no }=32)\end{array}$ & $P$ value \\
\hline Male, $n(\%)$ & $21(39.6 \%)$ & $12(37.5 \%)$ & 0.846 \\
\hline Age (year) ${ }^{a}$ & $55.26 \pm 9.24$ & $57.50 \pm 7.37$ & 0.248 \\
\hline Insulin therapy, $n$ (\%) & $23(43.4 \%)$ & $13(40.6 \%)$ & 0.538 \\
\hline Oral hypoglycemic therapy, $n(\%)$ & $30(56.6 \%)$ & $19(59.4 \%)$ & 0.538 \\
\hline Family history of DM, $n$ (\%) & $29(54.7 \%)$ & $15(46.9 \%)$ & 0.483 \\
\hline Hemoglobin $(g / d L)^{a}$ & $12.98 \pm 1.34$ & $13.07 \pm 1.05$ & 0.764 \\
\hline Leukocytes $(\times 103 / \mu \mathrm{L} \text { cells })^{\mathrm{a}}$ & $6.53 \pm 1.67$ & $6.53 \pm 1.91$ & 0.998 \\
\hline Platelets $(\times 103 / \mu \mathrm{L} \text { cells })^{\mathrm{a}}$ & $223.57 \pm 50.09$ & $206.56 \pm 53.82$ & 0.144 \\
\hline Albumin $(g / d L)^{a}$ & $4.25 \pm 0.42$ & $4.30 \pm 0.40$ & 0.622 \\
\hline Bilirubin, total $(\mathrm{mg} / \mathrm{dL})^{\mathrm{a}}$ & $0.81 \pm 0.15$ & $0.78 \pm 0.22$ & 0.436 \\
\hline$I R^{a}$ & $1.29 \pm 1.36$ & $1.41 \pm 1.75$ & 0.722 \\
\hline AST $(I U / L)^{a}$ & $50.65 \pm 24.36$ & $51.59 \pm 28.20$ & 0.871 \\
\hline $\operatorname{ALT}(I U / L)^{a}$ & $55.71 \pm 27.48$ & $64.13 \pm 35.90$ & 0.227 \\
\hline Creatinine $(\mathrm{mg} / \mathrm{dL})^{\mathrm{a}}$ & $1.02 \pm 0.86$ & $0.87 \pm 0.15$ & 0.304 \\
\hline $\operatorname{AFP}(\mathrm{ng} / \mathrm{mL})^{\mathrm{a}}$ & $7.08 \pm 5.01$ & $7.41 \pm 6.24$ & 0.789 \\
\hline HCV RNA viral load $(\log 10 \mathrm{IU} / \mathrm{mL})^{a}$ & $6.77 \pm 6.661$ & $6.77 \pm 6.640$ & 0.847 \\
\hline $\mathrm{HbA} 1 \mathrm{c}(\%)^{\mathrm{a}}$ & $8.17 \pm 0.58$ & $7.91 \pm 0.69$ & 0.062 \\
\hline FIB-4 ${ }^{b}$ score $^{a}$ & $1.89 \pm 0.85$ & $1.75 \pm 0.76$ & 0.442 \\
\hline
\end{tabular}

${ }^{a}$ Mean \pm SD. Glycemic improved group: $\geq 1 \%$ reduction of baseline HbA1c levels at SVR. Non-glycemic improved group: $<1 \%$ reduction of baseline HbA1c levels at SVR

AFP Alpha-fetoprotein, ALT Alanine transaminase, AST Aspartate transaminase, ${ }^{b}$ FIB-4 score $=$ [age 3AST]/[platelets 3 ALT1/2], INR international normalized ratio, HbA1c glycated hemoglobin

Table 2 Statistical comparison of the post-treatment parameters in glycemic improved patients versus glycemic non-improved patients

\begin{tabular}{|c|c|c|c|}
\hline & $\begin{array}{l}\text { Glycemic non-improved } \\
\text { Patients }(\text { no }=53 \text { ) }\end{array}$ & $\begin{array}{l}\text { Glycemic improved } \\
\text { Patients }(\text { no }=32)\end{array}$ & $P$ value \\
\hline Hemoglobin $(g / d L)^{a}$ & $12.25 \pm 1.44$ & $12.57 \pm 1.23$ & 0.289 \\
\hline Leukocytes $(\times 103 / \mu \mathrm{L} \text { cells })^{a}$ & $6.98 \pm 1.72$ & $6.58 \pm 2.03$ & 0.337 \\
\hline Platelets $(\times 103 / \mu \mathrm{L} \text { cells })^{\mathrm{a}}$ & $228.9 \pm 51.77$ & $217.31 \pm 47.82$ & 0.307 \\
\hline Albumin $(\mathrm{g} / \mathrm{dL})^{\mathrm{a}}$ & $4.28 \pm 0.39$ & $4.31 \pm 0.37$ & 0.664 \\
\hline Bilirubin, total $(\mathrm{mg} / \mathrm{dL})^{\mathrm{a}}$ & $0.67 \pm 0.16$ & $0.67 \pm 0.19$ & 0.848 \\
\hline$I_{N R}{ }^{a}$ & $1.07 \pm 0.06$ & $1.07 \pm 0.09$ & 0.992 \\
\hline AST $(I U / L)^{a}$ & $22.38 \pm 7.83$ & $24.53 \pm 8.27$ & 0.232 \\
\hline ALT (IU/L) $)^{a}$ & $23.87 \pm 9.43$ & $24.22 \pm 7.98$ & 0.861 \\
\hline Creatinine $(\mathrm{mg} / \mathrm{dL})^{\mathrm{a}}$ & $0.93 \pm 0.18$ & $0.88 \pm 0.15$ & 0.181 \\
\hline $\mathrm{HbA1c}(\%)^{a}$ & $7.91 \pm 0.79$ & $6.50 \pm 0.72$ & $<0.001$ \\
\hline $\operatorname{AFP}(n g / m L)^{a}$ & $6.43 \pm 4.09$ & $6.56 \pm 5.94$ & 0.906 \\
\hline FIB- $4^{b}$ score $^{a}$ & $1.38 \pm 0.47$ & $1.17 \pm 0.44$ & 0.039 \\
\hline
\end{tabular}


Table 3 Statistical comparison between pre-treatment and post-treatment parameters in glycemic improved patients

\begin{tabular}{|c|c|c|c|}
\hline & Pre-treatment (no = 32) & Post-treatment (no $=32$ ) & $P$ value \\
\hline Hemoglobin $(g / d L)^{a}$ & $13.07 \pm 1.05$ & $12.57 \pm 1.23$ & 0.002 \\
\hline 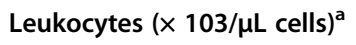 & $6.53 \pm 1.91$ & $6.58 \pm 2.03$ & 0.876 \\
\hline Platelets $(\times 103 / \mu \mathrm{L} \text { cells })^{\mathrm{a}}$ & $206.56 \pm 53.82$ & $217.31 \pm 47.82$ & 0.130 \\
\hline Albumin $(g / d L)^{a}$ & $4.30 \pm 0.40$ & $4.31 \pm 0.37$ & 0.501 \\
\hline Bilirubin, total $(\mathrm{mg} / \mathrm{dL})^{\mathrm{a}}$ & $0.78 \pm 0.22$ & $0.67 \pm 0.19$ & 0.009 \\
\hline$I_{N}{ }^{a}$ & $1.41 \pm 1.75$ & $1.07 \pm 0.09$ & 0.290 \\
\hline AST (IU/L) $)^{a}$ & $51.59 \pm 28.20$ & $24.53 \pm 8.27$ & 0.001 \\
\hline ALT (IU/L) ${ }^{a}$ & $64.13 \pm 35.90$ & $24.22 \pm 7.98$ & 0.001 \\
\hline Creatinine $(\mathrm{mg} / \mathrm{dL})^{\mathrm{a}}$ & $0.87 \pm 0.15$ & $0.88 \pm 0.15$ & 0.525 \\
\hline $\mathrm{HbA1c}(\%)^{a}$ & $7.91 \pm 0.69$ & $6.50 \pm 0.72$ & 0.001 \\
\hline $\operatorname{AFP}(n g / m L)^{a}$ & $7.41 \pm 6.24$ & $6.56 \pm 5.94$ & 0.032 \\
\hline FIB-4 ${ }^{b}$ score $^{a}$ & $1.75 \pm 0.76$ & $1.17 \pm 0.44$ & 0.001 \\
\hline
\end{tabular}

${ }^{a}$ Mean \pm SD. Glycemic improved group: $\geq 1 \%$ reduction of baseline HbA1c levels at SVR. Non-glycemic improved group: $<1 \%$ reduction of baseline HbA1c levels at SVR

AFP Alpha-fetoprotein, ALT Alanine transaminase, AST Aspartate transaminase, ${ }^{\mathrm{b}}$ FIB-4 score = [age 3AST]/[platelets 3 ALT1/2], INR international normalized ratio, $H b A 1 c$ glycated hemoglobin

Another report from Egypt by Dawood and his colleagues who included 460 T2DM patients with chronic $\mathrm{HCV}$ genotype 4 infection in order to evaluate the role of DAAs therapy on glycemic status. Their results showed that almost $77 \%$ of the patients achieved the improved glycemic control status after HCV-eradication by DAAs; moreover, the HbA1c and fasting blood glucose levels changed significantly 6 months following treatment [18].

In concordance with our findings, Pavone and his colleagues reported a statistically significant reduction in HbA1c, with a reduction of the mean value of $1.95 \%$, during the DAAs treatment [11]. The impact of HCV eradication on the glycemic control was also evaluated by Gilad and his colleagues who studied the clinical characteristics of 122 diabetic patients with chronic $\mathrm{HCV}$ infection; the authors reported that HbA1c at the nearest time point before treatment was $8.4 \% \pm 1.9 \%$, compared with $7.8 \% \pm 1.7 \%$ after treatment, a mean difference of $0.6 \%$ [9].

As regards to our patients who did not achieve the expected glycemic improvement at the end of therapy, this may be explained by two factors as proposed by Hashim et al. (2018); first, the etiology of T2DM in HCVinfected individuals has been postulated to result from either hepatogenous T2DM or classical T2DM due to

Table 4 Statistical comparison between pre-treatment and post-treatment parameters in glycemic non-improved patients

\begin{tabular}{|c|c|c|c|}
\hline & Pre-treatment $(\mathrm{no}=53)$ & Post-treatment $(\mathrm{no}=53)$ & $P$ value \\
\hline Hemoglobin $(\mathrm{g} / \mathrm{dL})^{\mathrm{a}}$ & $12.98 \pm 1.34$ & $12.25 \pm 1.44$ & 0.001 \\
\hline Leukocytes $(\times 103 / \mu \mathrm{L} \text { cells })^{a}$ & $6.53 \pm 1.67$ & $6.98 \pm 1.72$ & 0.038 \\
\hline Platelets $(\times 103 / \mu \mathrm{L} \text { cells })^{a}$ & $223.57 \pm 50.09$ & $228.91 \pm 51.77$ & 0.150 \\
\hline Albumin $(g / d L)^{a}$ & $4.25 \pm 0.42$ & $4.28 \pm 0.39$ & 0.249 \\
\hline Bilirubin, total $(\mathrm{mg} / \mathrm{dL})^{a}$ & $0.81 \pm 0.15$ & $0.67 \pm 0.16$ & 0.001 \\
\hline$I R^{a}$ & $1.29 \pm 1.36$ & $1.07 \pm 0.06$ & 0.253 \\
\hline AST $(I U / L)^{a}$ & $50.65 \pm 24.36$ & $22.38 \pm 7.83$ & 0.001 \\
\hline ALT (IU/L) ${ }^{a}$ & $55.71 \pm 27.48$ & $23.87 \pm 9.43$ & 0.001 \\
\hline Creatinine $(\mathrm{mg} / \mathrm{dL})^{\mathrm{a}}$ & $1.02 \pm 0.86$ & $0.93 \pm 0.18$ & 0.404 \\
\hline $\mathrm{HbA} 1 \mathrm{c}(\%)^{\mathrm{a}}$ & $8.17 \pm 0.58$ & $7.91 \pm 0.79$ & 0.001 \\
\hline $\operatorname{AFP}(\mathrm{ng} / \mathrm{mL})^{\mathrm{a}}$ & $7.08 \pm 5.01$ & $6.43 \pm 4.09$ & 0.012 \\
\hline FIB-4 ${ }^{b}$ score $^{a}$ & $1.89 \pm 0.85$ & $1.38 \pm 0.47$ & 0.001 \\
\hline
\end{tabular}

${ }^{a}$ Mean \pm SD. Glycemic improved group: $\geq 1 \%$ reduction of baseline HbA1c levels at SVR. Non-glycemic improved group: < $1 \%$ reduction of baseline HbA1c levels at SVR

AFP Alpha-fetoprotein, ALT Alanine transaminase, AST Aspartate transaminase, ${ }^{\mathrm{b}} \mathrm{FIB}-4$ score $=$ [age $\left.3 \mathrm{AST}\right] /[\mathrm{platelets} 3 \mathrm{ALT} 1 / 2]$, INR international normalized ratio, $H b A 1 c$ glycated hemoglobin 
virally mediated IR. Second explanation, HCV infection may affect glucose level by an autoimmune mechanism on $\beta$ cells and is not related to IR [19].

However, it should be noted that there were limitations in the present study; the sample size and the duration of follow-up, it is well established that the micro-vascular complications of diabetes, including nephropathy, neuropathy, and retinopathy, improve with lowered HbA1c level. Therefore, early treatment of $\mathrm{HCV}$ could potentially slow the onset and progression of micro-vascular complications of diabetes. Given the study period, we were unable to evaluate whether improved glycemic control was durable beyond 3 months. Therefore, larger studies with a longer duration of follow-up are recommended to validate these findings.

\section{Conclusion}

In conclusion, our study reported that HCV eradication with DAAs leads to a significant reduction in HbA1c level (HbA1C improvement of more than 1\%) in 37.6\% of patients with diabetes. Meanwhile, $62.4 \%$ patients showed a reduction in HbA1c level less than $1 \%$ at 12 weeks after the end of therapy. These findings raise the question to whether the HCV eradication may also impact the future morbidity due to T2DM and slowing the onset and progression of micro-vascular complications of diabetes, as well as the degree of improvement of hepatic fibrosis induced by chronic HCV. For this reason, close follow-up post-HCV treatment is needed, and large prospective studies are recommended to validate these results.

\section{Abbreviations \\ AFP: Alpha fetoprotein; CTP: Child-Turcotte-Pugh; CBC: Complete blood count; DAAs: Direct-acting antivirals; Hba1c: Hemoglobin A1c; Hbs Ag: Hepatitis B virus surface antigen; HCV: Hepatitis C virus; HCC: Hepatocellular carcinoma; HOMA: Homeostatic model assessment; IRB: Institutional Review Board; IR: Insulin resistance; INR: International normalized ratio; NCCVH: National Committee for Control of Viral Hepatitis; Peg: Pegylated interferon; RBV: Ribavirin; PT: Prothrombin time; \\ SVR: Sustained virological response; T2DM: Type 2 diabetes mellitus}

\section{Acknowledgements}

I wish to express my great appreciation to all those who assisted us to complete this work in the Tropical Medicine Department, Aswan University Hospital.

\section{Authors' contributions}

MME contributed in conception of the study design, clinical supervision and acceptance of the final form of the manuscript. DAA contributed in clinical examinations and collection of data. NHE contributed in statistical analysis and writing of the manuscript. MAA contributed in the laboratory investigations' design, supervision, and writing of the manuscript. All authors read and approved the final manuscript.

\section{Funding}

None.

Availability of data and materials

Data is available upon request.

\section{Ethics approval and consent to participate}

The study was performed according to the ethical guidelines of the 1975 Declaration of Helsinki after approval from Institutional Review Board (IRB) for human subject research at Aswan University Hospital (serial: 18-4-111-Aswu). An informed written consent was obtained from all enrolled participants before enrolment to the study.

\section{Consent for publication}

Non applicable.

\section{Competing interests}

The authors have no conflict of interest to declare.

\section{Author details}

${ }^{1}$ Department of Tropical Medicine and Gastroenterology, Faculty of Medicine, Aswan University, Aswan, Egypt. ${ }^{2}$ Department of Moleculer genetics, National Research Center, Cairo, Egypt. ${ }^{3}$ Department of Clinical Pathology, Faculty of Medicine, Ain Shams University, Cairo, Egypt.

Received: 17 July 2020 Accepted: 26 October 2020

Published online: 10 November 2020

References

1. Mohd Hanafiah K, Groeger J, Flaxman AD, Wiersma ST (2013) Global epidemiology of hepatitis C virus infection: new estimates of agespecific antibody to HCV seroprevalence. Hepatology (Baltimore, Md) 57(4):13331342

2. Petruzziello A, Marigliano S, Loquercio G, Cozzolino A, Cacciapuoti C (2016) Global epidemiology of hepatitis C virus infection: an up-date of the distribution and circulation of hepatitis C virus genotypes. World J Gastroenterol 22(34):7824-7840

3. Gower E, Estes C, Blach S, Razavi-Shearer K, Razavi H (2014) Global epidemiology and genotype distribution of the hepatitis $C$ virus infection. J Hepatol 61(1 Suppl):S45-S57

4. El-Ghitany E (2019) Hepatitis C virus infection in Egypt: current situation and future perspective. J High Inst Public Health 49(1):1-9. https://doi.org/10. 21608/jhiph.2019.29460

5. Hum J, Jou JH (2018) The link between hepatitis C virus and diabetes mellitus: improvement in insulin resistance after eradication of hepatitis $C$ virus. Clin Liver Dis (Hoboken) 11(3):73-76

6. Gaetano JN (2014) Benefit-risk assessment of new and emerging treatments for hepatitis C: focus on simeprevir and sofosbuvir. Drug Healthc Patient Saf 6:37-45

7. Delgado-Borrego A, Jordan SH, Negre B, Healey D, Lin W, Kamegaya Y (2010) Reduction of insulin resistance with effective clearance of hepatitis $C$ infection: results from the HALT-C trial. Clin Gastroenterol Hepatol 8(5):458462

8. Aghemo A, Prati GM, Rumi MG, Soffredini R, D'Ambrosio R, Orsi E, De Nicola S, Degasperi E, Grancini V, Colombo M (2012) Sustained virological response prevents the development of insulin resistance in patients with chronic hepatitis C. Hepatology 56(5):1681-1687

9. Gilad A, Fricker ZP, Hsieh A, Thomas DD, Zahorian T, Nunes DP (2019) Sustained improvement in type 2 diabetes mellitus is common after treatment of hepatitis C virus with direct-acting antiviral therapy. J Clin Gastroenterol 53(8):616-620

10. American Diabetes Association (2020) Standards of medical care in diabetes-2020. Diabetes Care 43(8):1981-1981. https://doi.org/10.2337/ dc20-ad08c

11. Pavone P, Tieghi T, d'Ettorre G, Lichtner M, Marocco R, Mezzaroma I, Vullo V (2016) Rapid decline of fasting glucose in HCV diabetic patients treated with direct-acting antiviral agents. Clin Microbiol Infect 22:462.e1-462.e3

12. Elgharably A, Gomaa Al, Crossey MM, Norsworthy PJ, Waked I, TaylorRobinson SD (2016) Hepatitis C in Egypt - past, present, and future. Int J Gen Med 10:1-6

13. Omran D, Alboraie M, Zayed RA, Wifi MN, Naguib M, Eltabbakh M, Abdellah M, Sherief AF, Maklad S, Eldemellawy HH, Saad OK, Khamiss DM, El Kassas M (2018) Towards hepatitis C virus elimination: Egyptian experience, achievements and limitations. World J Gastroenterol 24(38):4330-4340

14. Parvaiz F, Manzoor S, Iabal J, Sarkar-Dutta M, Imran M, Waris G (2015) Hepatitis C virus NS5A promotes insulin resistance through IRS-1 serine 
phosphorylation and increased gluconeogenesis. World J Gastroenterol 21(43):12361-12369

15. Hum J, Jou JH, Green PK, Berry K, Lundblad J, Hettinger BD, loannou GN (2017) Improvement in glycemic control of type 2 diabetes after successful treatment of hepatitis C virus. Diabetes Care 40:1173-1180

16. Ciancio A, Bosio R, Bo S, Pellegrini M, Sacco M, Vogliotti E, Fassio G, AGF BMD, Gallo M, Giordanino C, Terzi di Bergamo L, Ribaldone D, Bugianesi E, Smedile A, Rizzetto M, Saracco GM (2018) Significant improvement of glycemic control in diabetic patients with HCV infection responding to direct-acting antiviral agents. J Med Virol 90:320-327

17. Abdel Alem S, Elsharkawy A, Fouad R, Adel E, Abdellatif Z, Musa S, Nagy A, Hussein MS, Yosry A, Esmat GJ (2017) Improvement of glycemic state among responders to Sofosbuvir-based treatment regimens: single center experience. J Med Virol 89(12):2181-2187

18. Dawood AA, Nooh MZ, Elgamal AA (2017) Factors associated with improved glycemic control by direct-acting antiviral agent treatment in Egyptian type 2 diabetes mellitus patients with chronic hepatitis C genotype 4. Diabetes Metab J 41:316-321

19. Hashim AEM, Kandeel HT, Hendy OM, El-Mola K, El-Raey FM, Attia MSM (2017) Effect of new direct-acting antiviral drugs on insulin resistance and glycemic control after treatment of chronic hepatitis $C$ virus infection in type 2 diabetic patients. Al-Azhar Assiut Medical Journal 15:187-195

\section{Publisher's Note}

Springer Nature remains neutral with regard to jurisdictional claims in published maps and institutional affiliations.

\section{Submit your manuscript to a SpringerOpen ${ }^{\circ}$ journal and benefit from:}

- Convenient online submission

- Rigorous peer review

- Open access: articles freely available online

- High visibility within the field

- Retaining the copyright to your article

Submit your next manuscript at $\boldsymbol{\nabla}$ springeropen.com 